\title{
Queen Anne sign
}

\author{
Jane Kobylianskii MD, Wayne L. Gold MD
}

Cite as: CMAJ 2022 February 14;194:E219. doi: 10.1503/cmaj.211051

A

72-year-old man presented to the emergency department with progressive fatigue and intolerance to cold. He had a history of hypothyroidism and had chosen to discontinue his levothyroxine supplementation 6 months earlier. On examination, the patient was alert, with a temperature of $36^{\circ} \mathrm{C}$, blood pressure of $147 / 70 \mathrm{~mm} \mathrm{Hg}$, heart rate of 98 beats/minute and respiratory rate of 16 breaths/minute. We observed loss of the outer third of the eyebrows (i.e., the Queen Anne sign, Figure 1), periorbital edema, xerosis and thin hair. His mental status examination raised concern for the presence of delusions related to his medical care. The patient's thyrotropin level was 204 (normal 0.35-4.94) mIU/L, his free thyroxine and triiodothyronine levels were undetectable, and his creatine kinase (874 IU/L, normal $\leq 240)$ and serum creatinine $(166 \mu \mathrm{mol} / \mathrm{L}$, normal 64-110) levels were elevated.

We diagnosed severe hypothyroidism and initiated levothyroxine $1.6 \mu \mathrm{g} / \mathrm{kg}$ orally daily (the recommended initial full replacement dose). ${ }^{1}$ We admitted the patient to hospital because we suspected psychosis, which would have suggested a diagnosis of myxedema coma, possibly warranting intravenous thyroid hormone replacement. However, psychiatric consultation did not support this diagnosis. His biochemical parameters improved over several days with oral thyroid hormone replacement alone, and he was discharged.

Most of the common symptoms of hypothyroidism are associated with metabolic slowing, including fatigue, muscle weakness, weight gain, cold intolerance and constipation. ${ }^{2}$ Many of the physical findings relate to the progressive accumulation of glycosaminoglycans in interstitial spaces, such as edema and thinning and coarsening of hair. ${ }^{2}$ Queen Anne sign, likely named after a portrait of a queen of Denmark, is an uncommon finding in patients with hypothyroidism. ${ }^{3}$ It is associated with other diseases, including atopic dermatitis, hypoparathyroidism, leprosy and syphilis. ${ }^{3}$ In our patient, we attributed this finding to hypothyroidism because of the biochemical evidence of hypothyroidism and the

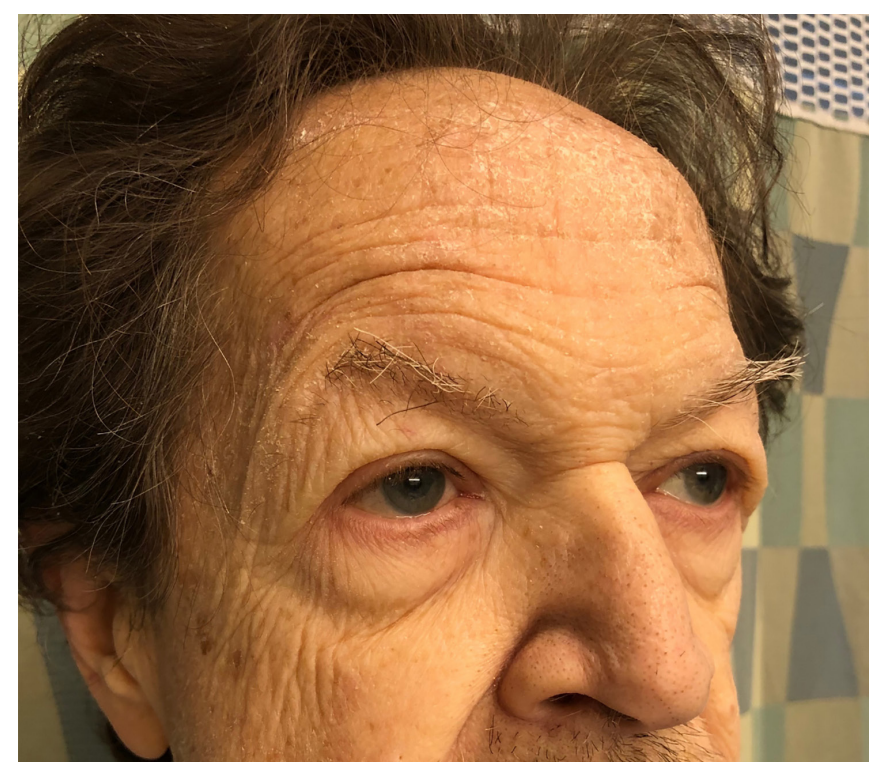

Figure 1: Loss of the outer third of the eyebrows, known as the Queen Anne sign, in a 72-year-old man with severe hypothyroidism. Dry skin is also apparent.

absence of clinical features suggesting other causes. Given the widespread availability of laboratory testing and treatment in Canada, severe hypothyroidism is uncommon. Untreated, it can progress to myxedema coma, multiorgan failure and death. ${ }^{2}$

\section{References}

1. Jonklaas J, Bianco AC, Bauer AJ, et al.; American Thyroid Association Task Force on Thyroid Hormone Replacement. Guidelines for the treatment of hypothyroidism: prepared by the American Thyroid Association task force on thyroid hormone replacement. Thyroid 2014;24:1670-751.

2. Heymann WR. Cutaneous manifestations of thyroid disease. J Am Acad Dermatol 1992;26:885-902.

3. Borzutzky A, Tejos-Bravo M, Venegas LF, et al. Hertoghe's sign in atopic dermatitis. J Pediatr 2020;226:299.

\section{Competing interests: None declared.}

This article has been peer reviewed.

The authors have obtained patient consent.

Affiliations: Department of Medicine (Kobylianskii, Gold), University of Toronto; Divisions of General Internal Medicine (Gold) and Infectious Diseases (Gold), University Health Network, Toronto, Ont.
Content licence: This is an Open Access article distributed in accordance with the terms of the Creative Commons Attribution (CC BY-NC-ND 4.0) licence, which permits use, distribution and reproduction in any medium, provided that the original publication is properly cited, the use is noncommercial (i.e., research or educational use), and no modifications or adaptations are made. See: https://creativecommons.org/licenses/by-nc-nd/4.0/

Correspondence to: Wayne Gold, wayne.gold@uhn.ca 